\title{
Toe Line Conveyor System - A Review
}

\author{
Mahesh Kanojiya*, Swapnil Bagde, Akshay Waghmare, Manjoor Ahmed, Aabha Dongre, Vikas Kumar \\ Mechanical Engineering Department, Nagpur Institute of Technology, Nagpur, Maharashtra, India
}

\begin{abstract}
In industries, it is very necessary to move the components from one area to the other in a regular basis making it desirable to minimize the workers involved in it. In this work we have designed a conveyor which can be used in industries. It is very necessary to send material from one place to another in an industry in a convenient manner and hence a need to find a way to transmit the materials and hence in this work we have made a conveyor model which is used for the material transformation from one end to another. This document provides the information of the toe line conveyor system which is designed and analyses ( theoretically) for implementing the conveyor system in the industry. The conveyor system is operated with the help of Bluetooth device. The system is semi automatic. The arnido is used for making the system semiautomatic. The system is capable of carrying the maximum load as per the requirement. A CAD model is prepared using the CATIA 3D modeling software.
\end{abstract}

Keywords : Conveyor System, Arnido, CATIA, Semiautomatic, Bluetooth

\section{INTRODUCTION}

Conveyors are a powerful material handling tool. They offer the chance to boost productivity, reduce material handling damage and minimize labour content in a manufacturing or distribution facility. Conveyors are normally classified as either Unit Load Conveyors that are designed to handle specific uniform units such as cartons or pallets, and Process Conveyors that are designed to handle loose product such as sand, grate, coffee, cookies, etc. which are fed to machinery for further operations or mixing. It is quite common for manufacturing plants to combine both Process and Unit Load conveyors in its operations.

Roller conveyor is not subjected to complex state of loading still we found that it is designed with higher factor of safety. If we redesigned critical parts e.g.
Roller, Shaft, Bearing \& Frame etc. then it is possible to minimize the overall weight of the assembly. Powered belt conveyors are considerable long (9000 meter to 10000 meter) as compared to roller conveyor. So we can achieve considerable amount of material saving if we apply above study related to roller conveyor to this belt conveyor.

A production line is commonly arranged in a series of workstations and each workstation consists of one or more parallel machines of the same type. To support the loading and unloading tasks for the parallel machines, the conveyors are generally employed as material handling equipment in modern industry. A great deal of research has mostly concentrated on controlling the conveyors with stoppage and queuing. For example, a design of conveyor-equipped material handling system with routing pallets was analyzed and simulated. Nevertheless, the stoppage of the 
closed loop queuing model often resulted in an expensive system. Therefore, the just-in-time (JIT) philosophy is presented to promote a better balance between the machine productivity and the conveyor speed for the material handling task in this study. Numerous real-time modelling designs with theoretical approaches to control the single or multiple conveyor system have been built, but none achieves the maximum profit. The profit and the production efficiency are mostly concerned with Problems challenging the manufacturing industry. Hence, the maximum profit is considered in this study as the objective of the overall production system, including the parallel machines and the conveyors.

In this study, the machine cost is divided into the operation and fixture costs. When the machines are idle or break down, the operation cost is negligible. This is in view of the fact that the consumption of input resources does not exist and the electricity costs of idle machines are relatively small compared with those of the entire system. Thus, when a machine is idle or breaks down, there exist only the repair costs. The marginal operation cost is a linear increasing function of the operation rate; therefore, the operation cost of the conveyor is also proposed in direct proportion to the square of the conveyor operating speed as in other researches. In fact, the higher operating speed of a conveyor requires a higher cost per unit speed. It is realistic to assume that increasing the unit conveyor speed results in a higher operating cost than costs at lower levels, such as maintenance and depreciation costs. In addition, the setup cost of a conveyor is considered in this study. For many years, the decision-making process at the shop-floor level has been propelled by the implicit idea of optimizing the service of machines, and the operational decision makings are still oriented towards finding an adequate balance between work load and machine capacity. However, as the advanced numerical control (NC) machines are extensively used from job shops to flexible manufacturing systems (FMSs), the material handling equipments for loading and unloading such systems becomes significant to the management. There is definitely an economic need not only to control the conveyor speed and the number of parallel machines, but also to find the optimum solution in reaching the maximum profit of a deterministic production quantity. Through this study, the control of the conveyor speed in optimizing the production of the machines and conveyors becomes concretely solvable.

\section{IDENTIFICATION OF PROBLEM}

When we had visited the industry we have taken the round on various locations or shops for identifying the problems in the industry. Following are the problems which we had identified.

1. Transportation problem: Here we have identified the transportation of the blanks from trimming section to the press shop. The transportation of the blanks was done with the help of human beings. The fully automated or semi automated systems was not available.

\section{PROBLEM ANALYSIS}

We know that every problem is having the solution. So first we have selected the problem of Transportation of blank of circular cut sheet from circular cut machine to press machine. We analysed the problem which may occur for preparing the solution of the transportation. We had seen that both the sections are at different level. The circular sheet cutting machine is at low level and punching press is at high level. So it is one of the difficulties for designing the transportation for the two different levels. Taking the measurements and deciding the 
dimensions of the layout and trolley or conveyor takes a time.

\section{OBJECTIVES OF THE WORK}

The following are the objectives of the study:

1. Study existing conveyor system.

2. Geometry modelling existing conveyor.

3. Analysis of existing roller conveyor.

4. Modification of critical conveyor parts for weight optimization.

5. Analysis of Modified design for same loading condition.

6. Recommendation of new solution with weight reduction.

\section{DESIGN CALCULATION}

\section{a) Design for Weight Calculation}

\section{Given data:}

Material $=$ Mild Steel

Density of Material $=780 \mathrm{~kg} / \mathrm{m} 3$

Diameter of Cylinder blank $=0.70 \mathrm{~m}$

Thickness of Blank $=0.0085 \mathrm{~m}$

We know that

Density $=$ Weight $/$ Volume

Therefore,

$$
\begin{aligned}
& \text { Weight }=\text { Density } \times \text { Volume } \\
& \text { Weight }=\text { Density } \times \text { Area } \times \text { thickness } \\
& \text { Weight }=7850 \times(3.14 / 4) \times \mathrm{D} 2 \times \mathrm{t} \\
& \text { Weight }=7850 \times(3.14 / 4) \times 0.72 \times 0.0085 \\
& \text { Weight }=10.57 \mathrm{Kg}
\end{aligned}
$$

Weight of a single plate $=10.57 \mathrm{Kg}$

Load to be carried on trolley is of 200 Plates i.e $n=200$ plates Therefore,

Total load of 200 plates will be $=200 \times 10.57$

$$
\begin{aligned}
& =2114.72 \mathrm{Kg} \\
& =2114.72 \times 9.81 \\
& =20.74 \mathrm{KN}
\end{aligned}
$$

b) Now for Diameter of $0.59 \mathrm{~m}$

$$
\begin{aligned}
& \text { Weight of single plate }=\text { Density } \times \text { Volume } \\
& \text { Weight }=\text { Density } \times \text { Area } \times \text { thickness } \\
& \text { Weight }=7850 \times(3.14 / 4) \times \mathrm{D} 2 \times \mathrm{t} \\
& \text { Weight }=7850 \times(3.14 / 4) \times 0.592 \times 0.0085 \\
& \text { Weight }=7.51 \mathrm{Kg} \\
& \text { Weight of a single plate }=7.51 \mathrm{Kg}
\end{aligned}
$$

Load to be carried on trolley is of 200 Plates i.e $n=200$ plates Therefore,

Total load of 200 plates will be $=200 \times 7.1$

$$
\begin{aligned}
& =1502.31 \mathrm{Kg} \\
& =1502.31 \times 9.81 \\
& =14.737 \mathrm{KN}
\end{aligned}
$$

\section{c) For safety considerations:}

Considering load per hour $=20.74 \mathrm{KN}$ i.e. load carried by the trolley in one hour is $20.74 \mathrm{KN}$

Taking factor o safety as 50\% more therefore

Total load carried by the trolley with factor of safety will be

Total load with FOS $=(1+($ FOS $)) \times$ Load of 200 Plates

Total load with FOS $=(1+(0.5)) \times 20.74$

Total load with FOS $=31.11 \mathrm{KN}$

\section{d) Design for Force \& Torque}

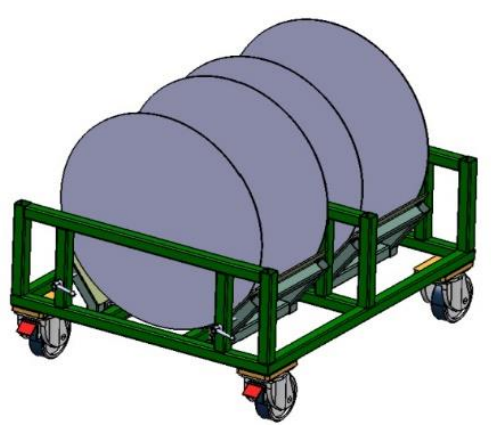

Fig. 1: Trolley Design 


\section{e) Given Data:}

Distance to be travelled by the trolley $=200 \mathrm{~m}$

Angle of inclination $(\theta)=8.9$ Degree

Coefficient of Friction $(\mu)=0.0015$ for deep groove ball bearing

Force on bearing $(\mathrm{F})=\mu \mathrm{x} \mathrm{m} \times \mathrm{g} \times \cos (\theta)$

$=0.0015 \times 31.11 \times 1000 \times \cos (8.9)$

$=46.11 \mathrm{~N}$

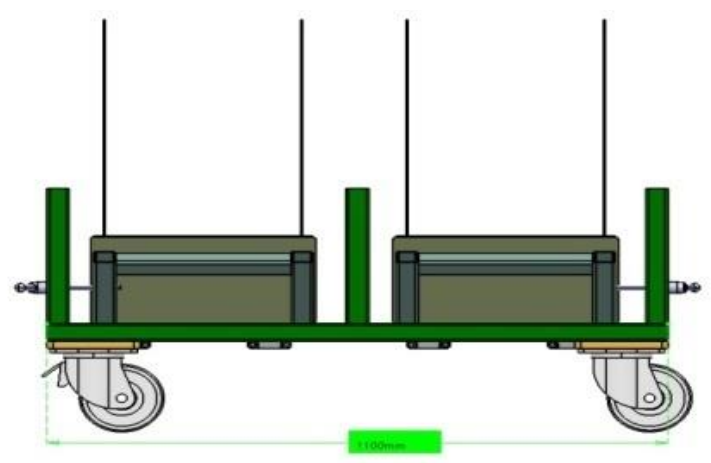

Fig. 2 Dimensions of Trolley

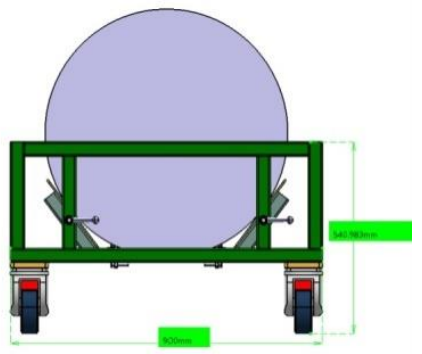

Fig. 3 Dimensions of Trolley

We know that Torque $(\mathrm{T})=$ force $\mathrm{x}$ length $\mathrm{x} \sin (\theta)$

Torque $(\mathrm{T})=46.11 \times 2.0 \times \sin (8.9)$

Torque $(\mathrm{T})=141.1 \mathrm{Nm}$

\section{f) Design for Velocity \& Acceleration}

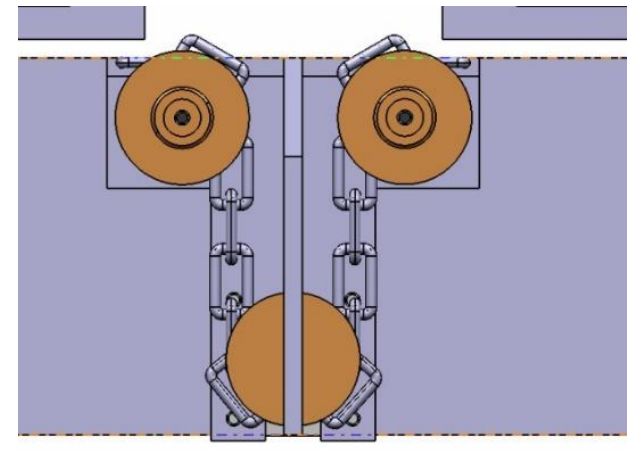

Fig. 4: Driving Mechanism

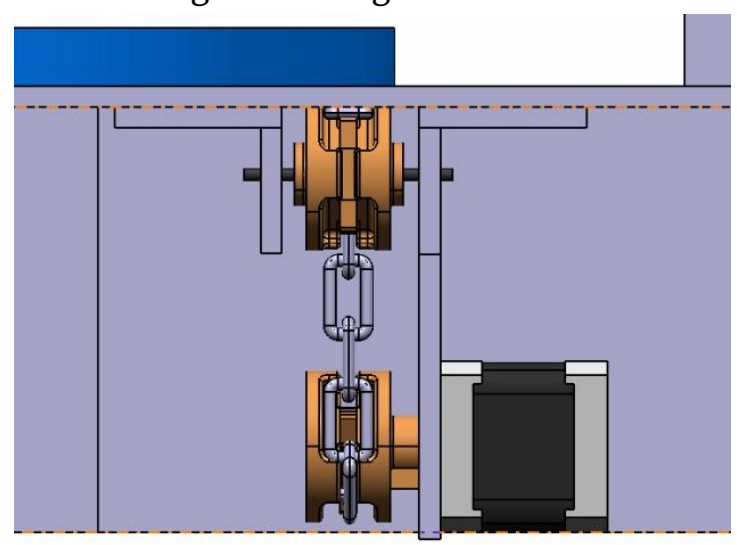

Fig. 5: Driving Mechanism

Total distance to be travelled $=56 \mathrm{~m}$

Considering time $=10 \mathrm{Min}=10 \times 60 \mathrm{Sec}=600 \mathrm{Sec}$

Velocity $=$ Distance $/$ Time

Velocity $=56 / 600=0.0933 \mathrm{~m} / \mathrm{Sec}$

Angular velocity $(\omega)-\mathrm{v} / \mathrm{r}=0.0933 / 75 \times 10-3=1.244 \mathrm{rad}$ Note: Diameter of the Chain sprocket is $150 \mathrm{~mm}$

Therefore, radius is $75 \mathrm{~mm}=75 \times 10^{-3} \mathrm{~m}$

We know that angular velocity is $\omega=(2 \times 3.14 \times \mathrm{N}) / 60$ Therefore, $\mathrm{N}=(\omega \times 60) /(2 \times 3.14)$

$$
\mathrm{N}=(1.244 \times 60) /(2 \times 3.14)=11.879 \mathrm{Rpm}
$$

\section{g) Calculation for stresses:}

Considering the shaft of the trolley as a simply supported beam and calculating the stresses induced in the shaft and shear force and bending moment. As the plate is of $710 \mathrm{~mm}$ considering the uniformly distributed load over the beam. Let us assumes that the beam is simply supported at the ends. 
Self weight of the beam

Total $\mathrm{C} / \mathrm{s}$ area $=\left(\mathrm{h}_{\mathrm{o}} \mathrm{X} \mathrm{w}_{\mathrm{o}}\right)-\left(\mathrm{h}_{\mathrm{i}} \mathrm{X} \mathrm{w}_{\mathrm{i}}\right)$

$$
\begin{aligned}
& =(40 \times 40)-(36 \times 36) \\
& =304 \mathrm{~mm}^{2} \\
& =0.304 \times 10^{-3} \mathrm{~m}^{2}
\end{aligned}
$$

Moment of Inertia $(\mathrm{I})=\left[\left(\mathrm{wo}_{\mathrm{o}} \mathrm{xh}_{\mathrm{o}^{3}}\right) / 12\right]-\left[\left(\mathrm{wix} \mathrm{h}_{\mathrm{i}}{ }^{3}\right) / 12\right]$

$$
\begin{aligned}
& =\left[\left(40 \times 40^{3}\right) / 12\right]-\left[\left(36 \times 36^{3}\right) / 12\right] \\
& =73365.33 \mathrm{~mm}^{4} \\
& =7.336 \times 10^{-8} \mathrm{~mm}^{4}
\end{aligned}
$$

Section Modulus $(\mathrm{Z})=\left[\left(\mathrm{w}_{\mathrm{o}} \mathrm{x} \mathrm{h}_{\mathrm{o}}{ }^{2}\right) / 16\right]-\left[\left(\mathrm{wi}_{\mathrm{i}} \mathrm{h}^{3}\right) / 6 \mathrm{x}\right.$ $h_{\circ}$ ]

$$
\begin{aligned}
& =\left[\left(40 \times 40^{2}\right) / 6\right]-\left[\left(36 \times 36^{3}\right) / 6 \times 40\right] \\
& =3668.267 \times 10^{-9} \mathrm{~m}^{3}
\end{aligned}
$$

Therefore the self weight of the beam will be

Volume of rod $=\mathrm{C} / \mathrm{s}$ area $\mathrm{x}$ length

Volume of rod $=304 \times 1000$

Volume of rod $=0.304 \times 10^{-3} \mathrm{~m}^{2}$

We know that weight $=$ density $\mathrm{x}$ volume

$$
\begin{aligned}
\text { Weight } & =7850 \times 0.304 \times 10^{-3} \\
& =2.3864 \mathrm{~kg}
\end{aligned}
$$

The weight of the rod is so small a compare to the weight of plates so neglecting the weight of the beam.

\section{h) Bending Moment on Beam:}

Weight $=3261 \mathrm{Kg}=31.99 \mathrm{KN}$

Maximum Bending Moment

$\left(\mathrm{M}_{\max }\right)=\mathrm{Wl} / 8=31.99 \times 10^{3} \times 1000 / 8=3.99 \mathrm{KN} \mathrm{m}$

Deflection of Beam $\left(\mathrm{Y}_{\text {Max }}\right)=(\mathrm{B} / 384) \times(\mathrm{Wl} / \mathrm{EI})$

$\left.=(5 / 384) \times\left(31.99 \times 10^{3} \times 1000\right) / 200 \times 7.3365 \times 10^{-8}\right)$

$=28.38 \mathrm{~mm}$

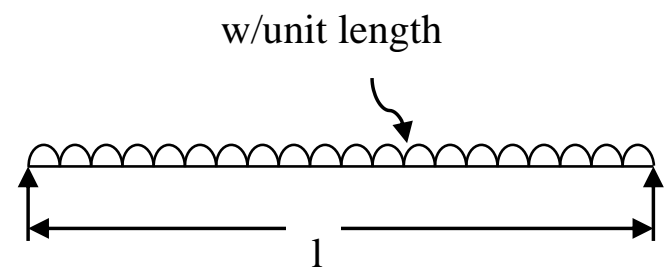

Fig 6: Simply Supported Beam

\section{CONCLUSION}

The conclusion of project work carried out is that the requirement of the industry has been satisfied. The time required for the transportation of the material by the human being is more as compare to the toe line conveyor system.

\section{REFERENCES}

[1]. M. A. Alspaugh, 2004 "Latest Developments in Belt Conveyor Technology", MINExpo Las Vegas, NV, USA September 27, 2004.

[2]. S.H. Masood, A.B. Shayan, E.Kara, 2005 "An investigation into design and mechanical conveyors systems for food processing", Advance Manufacturing Technology,25: 551-559,2005

[3]. N.Dima, N.Ahmed 2007 "Survey Of Research In Modeling Conveyor - based Automated Material Handling System In Wafer Fabs" ,Winter Simulation Conference,2007.

[4]. C.H. Lann 2008 "The design of a multi-conveyor system for profit maximization" ,Advance Manufacturing Technology , 22: 510-521,2008.

[5]. L. Pavlov,A. Krajnc and D.Beg 2008 "Cost function analysis in the structural optimization of steel frames" 2008

[6]. R. John, 2005 "Reliability Modeling and Optimization of Powered Roller Conveyors," Flexible Automation and Intelligent Manufacturing, FAIM Vol. 2, pp. 552-557, 2005.

\section{Cite this article as :}

Mahesh Kanojiya, Swapnil Bagde, Akshay Waghmare, Manjoor Ahmed, Aabha Dongre, Vikas Kumar, "Toe Line Conveyor System - A Review", International Journal of Scientific Research in Science and Technology (IJSRST), Online ISSN : 2395-602X, Print ISSN : 2395-6011, Volume 7 Issue 2, pp. 513-517, March-April 2020. Available at doi : https://doi.org/10.32628/IJSRST207294 Journal URL : http://ijsrst.com/IJSRST207294 